"This accepted author manuscript is copyrighted and published by Elsevier. It is posted here by agreement between Elsevier and MTA. The definitive version of the text was subsequently published in [Thermochimica Acta 647, 62-69, 2017, https://doi.org/10.1016/j.tca.2016.11.013]. Available under license CC-BY-NC-ND." 


\title{
In situ Evolved Gas Analysis Assisted Thermogravimetric (TG- FTIR and TG/DTA-MS) Studies on Non-activated Copper benzene-1,3,5-tricarboxylate
}

\author{
Andrea Domán ${ }^{\mathrm{a}}$, János Madarász ${ }^{\mathrm{b}}$, Krisztina László ${ }^{\mathrm{a}^{*}}$

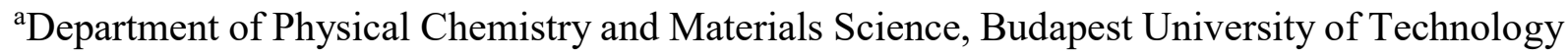 \\ and Economics, 1521 Budapest, Hungary \\ ${ }^{b}$ Department of Inorganic and Analytical Chemistry, Budapest University of Technology and \\ Economics, 1521 Budapest, Hungary ,
}

*Corresponding author

Krisztina László:

E-mail: klaszlo@mail.bme.hu, Phone: +36-1-463-1893, Fax: +36-1-463-3767

Email of the authors:

János Madarász: madarasz@mail.bme.hu

Andrea Domán: doman.andrea@mail.bme.hu

\begin{abstract}
The results of a complete thermogravimetric study of copper benzene-1,3,5-tricarboxylate (CuBTC or HKUST-1) are reported here together with mass spectrometry (MS) and Fourier transform infrared spectroscopy (FTIR) analyses of the evolved gases up to $800{ }^{\circ} \mathrm{C}$. Oxidative and inert conditions were applied to reveal the stoichiometry of the as-received synthesis product. In spite of using a water-ethanol mixture during the synthesis and the filtration only water is retained in the pores. It is proposed that the thermolytic release of ethanol in the temperature range $150-250{ }^{\circ} \mathrm{C}$ originates from ethanol - benzene-1,3,5-tricarboxylate (BTC) esters situated on the surface of the HKUST-1 crystal, and which limit the size of the developing crystals during the synthesis.
\end{abstract}

Keywords: HKUST-1, metal organic framework, MOF, simultaneous TG/DTA-MS, TGFTIR, XRD 


\section{Introduction}

In the current quest for energy storage systems, a new type of porous material with immense technological potential has recently emerged [1-4]. The outstandingly large adsorption capacity of porous metal organic frameworks (MOFs) is a consequence of their unique pore structure. MOFs are composed of transition metal ions or clusters linked together by organic ligands. Those that form a three-dimensional open framework with ordered and permanent pore structure are relevant for gas storage application.

Copper benzene-1,3,5-tricarboxylate, also commercialized as Basolite $\AA$ C 300 , is one of the most intensively studied MOFs. Its 3D network can adsorb extraordinarily large amounts of methane, and it is therefore a very promising material for storing low carbon dioxide emission fuels. They have notably met the US DoE target (180 times their own volume at 35 bar) for storage of natural gas [5]. This molecule was first reported in 1999 by Chui et al. [6] as HKUST-1. In this MOF copper(II) is the metal cation and benzene-1,3,5-tricarboxylate (BTC) anion is the tridentate organic linker. The dimeric $\mathrm{Cu}$-containing paddle-wheel units are linked by the polydental trimesate anion and form an electrically neutral three-dimensional porous network. This arrangement results in two unsaturated copper sites per paddle-wheel, which is ready to interact with polar molecules [2, 4, 6-8]. During the synthesis the axial coordination sites of the copper paddle-wheel units become occupied by solvent molecules, and thus each copper is able to complete its pseudo-octahedral coordination sphere [4, 6, 8]. Chui et al. prepared HKUST-1 by solvothermal synthesis in an ethanol-water mixture [6]. Thermogravimetric analysis (TGA) of their sample revealed that beside the 1-1 water molecules coordinated to each copper(II) cation there are 10 additional water molecules per HKUST-1 unit in the pores [6]. That is, the structure can accommodate more water than the "stoichiometric" amount, as solvent molecules may also be stored in the pores. The solvent can be completely removed by heat treatment in vacuum: when heated to ca $180{ }^{\circ} \mathrm{C}$ (also called activation $[8,9])$ the water molecules evaporate, leaving behind free copper sites, empty pores and thus high apparent surface area. Activation can also be followed by the naked eye, as the bright blue crystals turn dark blue.

Thermogravimetry (TG) is the key method for providing information on the volatile content and the temperature stability of the MOF samples that is essential in optimizing the activation conditions [1, 10-19]. The TG tests are run mostly in an inert, non-oxidizing atmosphere (e.g. $\mathrm{N}_{2}$, Ar or He), mimicking the thermal activation usually performed in vacuum at elevated temperature. The stability zone is the temperature range where the release of volatiles is practically complete but decomposition of the metal-organic framework has not yet started. The usual conclusion is that the overall amount of solvent released and the high temperature end of the release are influenced by the sample preparation (synthesis and drying) and by pre-treatment conditions (storage, pre-activation). In an inert atmosphere, the HKUST1 network collapses at about $300-380^{\circ} \mathrm{C}[10-12,20,21]$. Already around $250{ }^{\circ} \mathrm{C}$ the material may start to degrade both in inert [13] and in oxidative [16, 17] atmospheres. Application of inert conditions does not prevent or delay any radical degradation process, but only slows down the weight losses, which are usually rapid results of the presence of oxygen molecules as biradicals. That is why the temperature range of decomposition of HKUST-1 in air is generally narrower than in inert conditions $[16,18,22]$.

Beside observing the fast and complete decomposition process in the place of gradual degradation, employment of air in the TG tests up to $800-900^{\circ} \mathrm{C}$ has an additional advantage in the case of copper-containing metal complexes [23-27], namely the opportunity to calculate almost quantitatively both the copper (oxide) content (together with the corresponding stoichiometric amounts of ligands) and the apparent formula weight. From this the ratio of guest 
molecules/solvents incorporated in the lattice can be verified independently of the expected formula of the metal complex.

Here we report the results of our detailed TG analysis coupled with Fourier transform infrared spectroscopy (TG-FTIR) and simultaneous TG and differential thermal analysis coupled with mass spectrometry (TG/DTA-MS) measurements of the evolving gases up to 800 ${ }^{\circ} \mathrm{C}$, carried out both in oxidative and inert conditions, i.e. in air and helium, respectively. This combination of experimental techniques and difference in effect of the atmosphere on the thermal behaviour of HKUST-1 helped us to validate its crystalline composition, including some outward ethyl ester derivatives covering the surface of the as-synthesized crystals.

\section{Experimental}

\subsection{Materials}

Benzene-1,3,5-tricarboxylic acid $\left(\mathrm{H}_{3} \mathrm{BTC}\right)$, copper(II) nitrate trihydrate $\left(\mathrm{Cu}\left(\mathrm{NO}_{3}\right)_{2} \cdot 3 \mathrm{H}_{2} \mathrm{O}\right)(99.5 \%)$ and ethanol $\left(\mathrm{CH}_{3} \mathrm{CH}_{2} \mathrm{OH}\right)(99.5 \%)$ were purchased from Merck. All chemicals were used without further purification. High purity water of Millipore grade was used for the synthesis.

\subsection{Synthesis of HKUST-1}

HKUST-1 $\left(\mathrm{C}_{18} \mathrm{H}_{6} \mathrm{Cu}_{3} \mathrm{O}_{12}\right.$, Mw 604.87) was synthesized under solvothermal conditions after Wang et al. [28]. $10 \mathrm{~cm}^{3}$ of $83.3 \mathrm{mmol} \mathrm{dm}{ }^{-3} \mathrm{H}_{3} \mathrm{BTC}$ dissolved in ethanol was mixed with the stoichiometric amount of aqueous solution $\mathrm{Cu}\left(\mathrm{NO}_{3}\right)_{2} \cdot 3 \mathrm{H}_{2} \mathrm{O}\left(125 \mathrm{mmol} \mathrm{dm}{ }^{-3}, 10 \mathrm{~cm}^{3}\right)$ After 10 minutes argon gas was bubbled through the mixture for 5 minutes to eliminate air from the autoclave prior to sealing. The mixture was heated to $80{ }^{\circ} \mathrm{C}$ (heating rate $0.5{ }^{\circ} \mathrm{C} \mathrm{min}{ }^{-1}$ ), kept there for 24 hours and allowed to cool to room temperature (Scheme 1). The turquoise crystals obtained were filtered and thoroughly washed with ethanol. After that the material was dried in air for 24 hours at ambient temperature and stored for further use in a desiccator filled with freshly activated silica. The fine crystalline material was investigated without further crushing or grinding. The theoretical composition of the solvent-free HKUST- 1 is $31.5 \mathrm{w} / \mathrm{w} \%$ copper and $68.5 \mathrm{w} / \mathrm{w} \%$ organic ligand. The organic ligand/copper ratio is 2.17 .

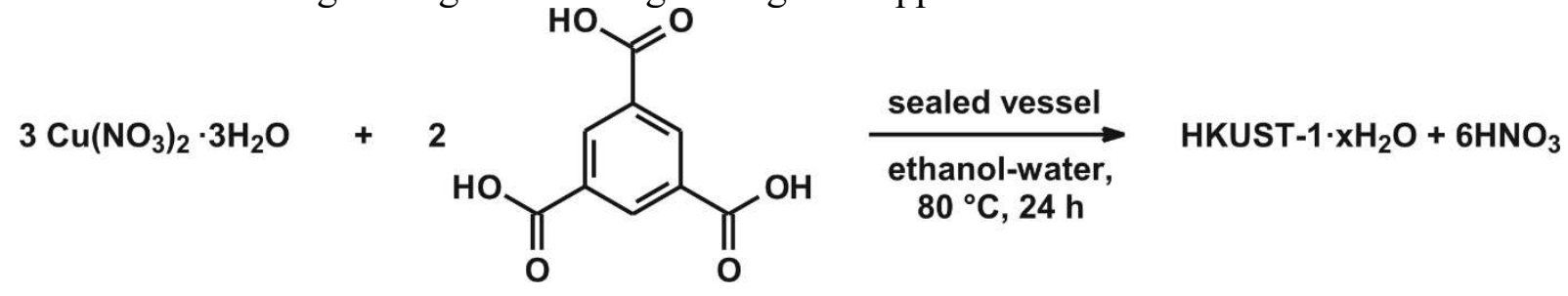

Scheme 1. Solvothermal synthesis of the non-activated HKUST-1

\subsection{Powder X-ray diffraction (XRD)}

The XRD patterns were obtained in the range $2 \theta=4-84^{\circ}$ with an X'pert Pro MPD (PANanalytical Bv., The Netherlands) X-ray diffractometer using an X'celerator type detector and $\mathrm{Cu} \mathrm{K} \mathrm{K}_{\alpha}$ radiation with a Ni filter foil $(\lambda=1.5408 \AA)$ on a 'zero-background Si single crystal' sample holder. Phase identification was assisted by the Search Match algorithm of High Score Plus (PANanalytical Bv.) software, based on either the international Powder Diffraction File (PDF4+, Release 2015, International Centre of Diffraction Data, ICDD, Pennsylvania, USA), or The Cambridge Structural Database (CSD-Enterprise, version 5.37, Cambridge Crystallographic Data Centre, CCDC [29]) using the built-in powder pattern generator algorithm of Mercury program [30]. Solid residues obtained at $325^{\circ} \mathrm{C}$ in air, and at $800^{\circ} \mathrm{C}$ both in air and helium from the furnaces of thermoanalytical instruments, are similarly subjected to 
phase analysis. The composition of the copper oxide phases were calculated with the help of Reference Intensity Ratio (RIR) method of XRD. $\mathrm{CuO}$ (tenorite, PDF No. 04-015-5873), $\mathrm{RIR}=3.70 ; \mathrm{Cu}_{2} \mathrm{O}$ (cuprite, PDF No. 01-80-3714), $\mathrm{RIR}=8.28$ was applied, respectively.

\subsection{Nitrogen adsorption}

Nitrogen adsorption/desorption isotherms were measured before and after activation at $-196{ }^{\circ} \mathrm{C}$ by a NOVA 2000e (Quantachrome, USA) volumetric computer-controlled surface analyzer. The samples were outgassed at room temperature (before activation) and at $180{ }^{\circ} \mathrm{C}$ (after activation). The apparent surface areas $S_{B E T}$ and $S_{L}$ were calculated using the BrunauerEmmett-Teller (BET) and the Langmuir models, respectively [31, 32]. The total pore volume $V_{\text {tot }}$ was derived from the amount of vapor adsorbed at relative pressure $p / p_{0} \rightarrow 1$, assuming that the pores are filled with liquid adsorbate. Transformation of the primary adsorption data and pore size analysis were performed with the Quantachrome ASiQwin software (version 3.0).

\subsection{Simultaneous thermogravimetry and differential thermal analysis - mass spectroscopy (TG/DTA-MS)}

The analysis was performed using a simultaneous TG/DTA apparatus (STD 2960 Simultaneous DTA-TGA, TA Instruments Inc., USA). The heating rate was $10{ }^{\circ} \mathrm{C} \mathrm{min}{ }^{-1}$, with a dry air flow of $130 \mathrm{~cm}^{3} \mathrm{~min}^{-1}$. The sample of $10.15 \mathrm{mg}$ was placed in an open Pt crucible. The evolving gas mixture was fed into a ThermoStar GDS 200 (Balzers Instruments) quadrupole mass spectrometer equipped with a Chaneltron detector, through a heated $100 \%$ methyl deactivated fused silica capillary tubing maintained at $\mathrm{T}=200{ }^{\circ} \mathrm{C}$. Data collection was carried out with QuadStar 422v7.02 software in scanning (SCAN) mode in the range of $\mathrm{m} / \mathrm{z}=1-300$.

\subsection{Thermogravimetry- Fourier transform infrared spectroscopy (TG-FTIR)}

A TGA 2050 Thermogravimetric Analyzer (TA Instruments, USA) was used for this experiment. The heating rate was $10^{\circ} \mathrm{C} \mathrm{min}^{-1}$, with dry air or helium $(99.996 \%$ ) flow rate of $120 \mathrm{~cm}^{3} \mathrm{~min}^{-1}$ (with an extra $10 \mathrm{~cm}^{3} \mathrm{~min}^{-1}$ air as a balance purge). The sample size was 23.66 or $24.34 \mathrm{mg}$, respectively, in an open Pt crucible. Gaseous species evolved from the sample were fed into the FTIR-gas cell of the BioRad TGA/IR Accessory Unit equipped with a Peltiercooled DTGS detector through a heated stainless steel transfer line $(1=90 \mathrm{~cm}$, din $=2 \mathrm{~mm})$ kept at $\mathrm{T}=180^{\circ} \mathrm{C}$. FTIR spectra $\left(500-4,000 \mathrm{~cm}^{-1}\right)$ were collected every $30 \mathrm{~s}$, after accumulating 29 interferograms, by a BioRad Excalibur Series FTS 3000 spectrometer using Win IR Pro 2.7 FTIR (BioRad) data collection and evaluation software.

\section{Results and discussion}

\subsection{Characterisation}

\subsubsection{XRD phase identification}

The resulting diffraction profile (Fig. 1) was compared to several relevant reference patterns of various hydrated or anhydrate forms of $\mathrm{Cu}_{3}(\mathrm{BTC})_{2}$ structures found in both the international CSD single crystal and PDF-4+ powder diffraction databases, namely as FIQCEN [33], DOTSOV42 [34] and PDF 00-062-1183 [35], PDF 00-64-0936 [36], and PDF 00-0651028 [37], respectively. These reference patterns, which were usually obtained after a preliminary activation process, are quite similar to each other (not shown). Apart from the variation in their water content, they do not exhibit any real differences. The peak positions of our non-activated sample agree well with those of the references, except for the (111) reflection, which was not observed at all. This is probably because of some preferential orientation in the measured crystalline powder, which also explains some slight differences in the relative 
intensities of the diffraction peaks observed in comparisons. Based on this analysis, our nonactivated crystalline sample is free from any copper oxides.

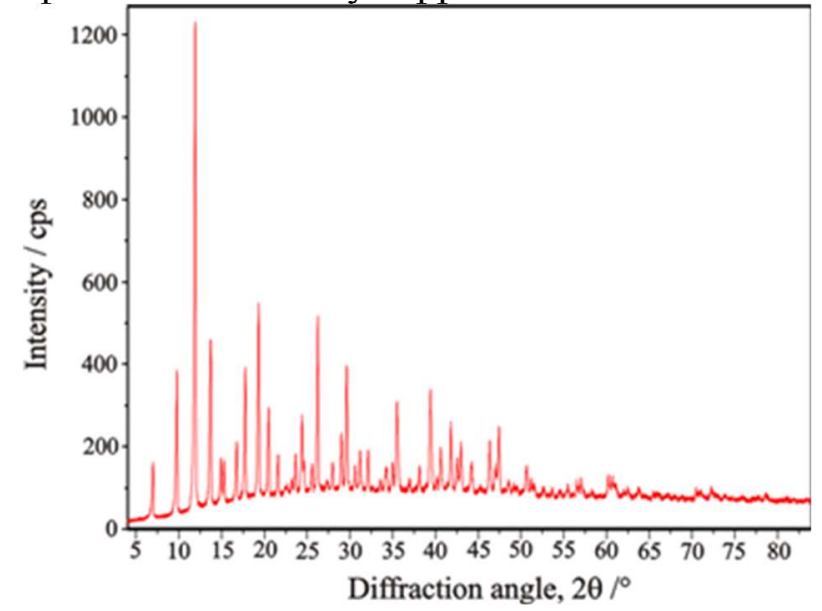

Fig. 1 Experimental XRD profile of the prepared non-activated sample

\subsubsection{Physico-chemical characterizations.}

The typical L-shaped isotherm of the non-activated HKUST-1 is shown in Fig. 2 (open symbols). Removal of the solvent during a $24 \mathrm{~h}$ treatment in vacuum at $180{ }^{\circ} \mathrm{C}$ (activation) results not only in a spectacular change in the colour of the material (Fig. 3) but also doubles the apparent surface area and pore volume (Table 1). Based on the pore volume of the activated samples the sample could theoretically accommodate ca 17 water molecules (assuming liquid state) per HKUST-1 unit.

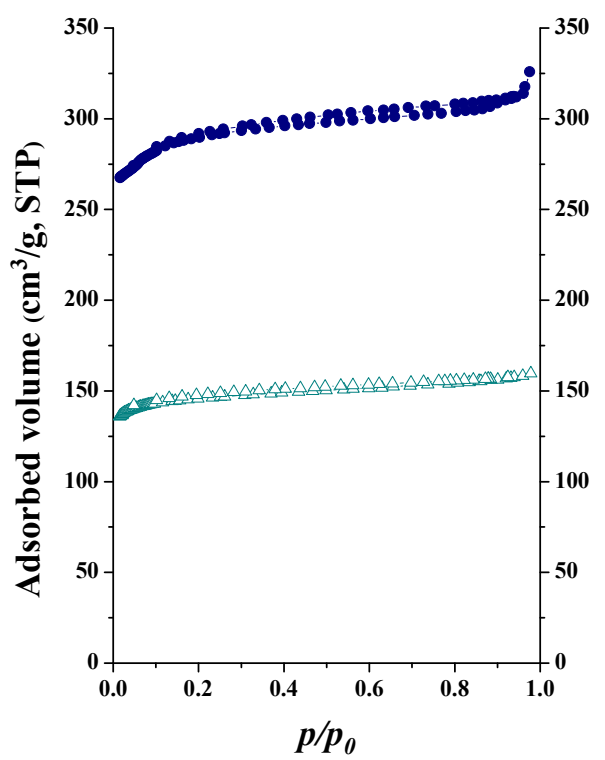

Fig. 2 Low temperature nitrogen adsorption isotherms of HKUST-1 before (open triangle) and after (filled symbols) activation 


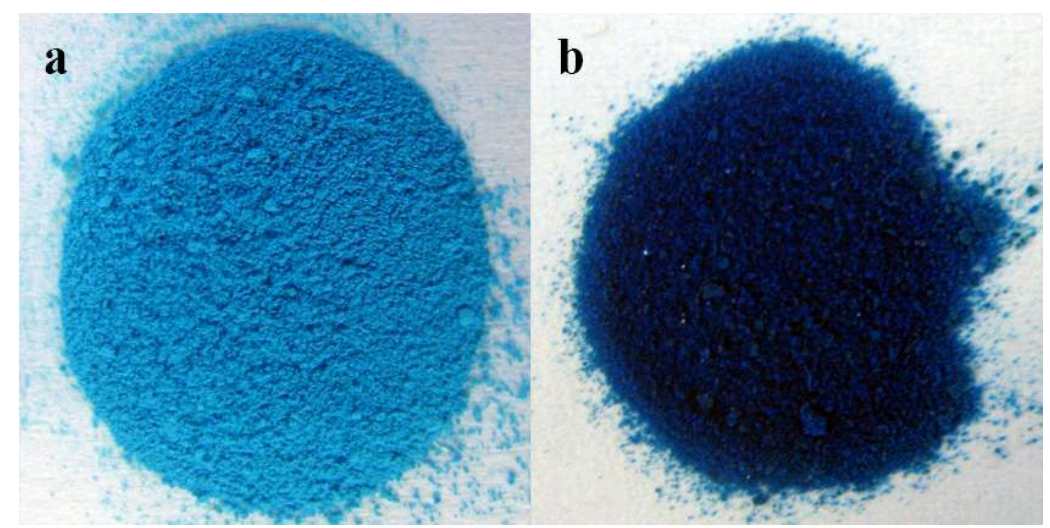

Fig. 3 HKUST-1 (a) before and (b) after activation

Table 1

Data deduced from low temperature $\left(-196^{\circ} \mathrm{C}\right)$ nitrogen adsorption measurements before and after activation.

\begin{tabular}{llll}
\hline Sample & $\begin{array}{l}S_{B E T} \\
{\left[\mathrm{~m}^{2} \mathrm{~g}^{-1}\right]}\end{array}$ & $\begin{array}{l}S_{L} \\
{\left[\mathrm{~m}^{2} \mathrm{~g}^{-1}\right]}\end{array}$ & $\begin{array}{l}V_{\text {tot }} \\
{\left[\mathrm{cm}^{3} \mathrm{~g}^{-1}\right]}\end{array}$ \\
\hline HKUST-1 before activation & 590 & 645 & 0.25 \\
HKUST-1 after activation $\left(180^{\circ} \mathrm{C}, 24 \mathrm{~h}\right)$ & 1140 & 1280 & 0.50 \\
\hline
\end{tabular}

\subsection{Thermogravimetric analyses in both air and helium}

The thermal stability of our HKUST-1 material was investigated in air by simultaneous TG/DTA (coupled with MS, Fig. 4), and in oxidative and in inert atmospheres by TG (coupled with FTIR spectroscopic gas cell, Fig. 5). Although in most of the cases only two steps are recognized in the literature, we were able to identify several weight loss stages in the TG curves both in air and in helium (Figs. 4 and 5, Table 2). Unanimously, the first step in the $100-150{ }^{\circ} \mathrm{C}$ range is attributed to the loss of the solvent $[1,10-13,20,38-40]$. The extent and dynamics of the mass loss in this regime is influenced by the synthesis and washing conditions as well as by the sample preparation preceding the thermal analysis $[10,19]$.

Our preliminary TGA investigation on non-activated HKUST-1 samples synthesised in various solvents and solvent mixtures showed that the position of this peak was independent of the solvent, implying that if water is present in any step of the synthesis (as a reaction medium or washing agent), it almost exclusively fills the pores. Therefore, in the thermogram detected in air we now attribute the first weight loss stage up to ca $160{ }^{\circ} \mathrm{C}$ to release of water (Fig. 4). The relatively high evaporation temperature is related to the confinement effect in the highly microporous HKUST-1 as well as possible chemisorption, while the detailed dynamics of this step can be associated with the three-modal pore size distribution of the material $(0.5,1.1$ and $1.35 \mathrm{~nm})[41]$.

We also observed a second TG step with small mass loss (almost 3\%) in the 160-250 ${ }^{\circ} \mathrm{C}$ region. According to the enlarged DTG signal this is a - more or less - separate weight loss stage, accompanied with a clearly identifiable exothermic heat effect (Fig. 4 inset). This feature is either overlooked in the literature or - for samples obtained in aqueous synthesis - attributed to the release of chemisorbed water [14, 17, 21, 42]. As thermal activation of HKUST-1 is often performed at $180{ }^{\circ} \mathrm{C}$, the clarification of this step may help to understand the processes that occur during the activation. 
TG, Weight $/ \%$

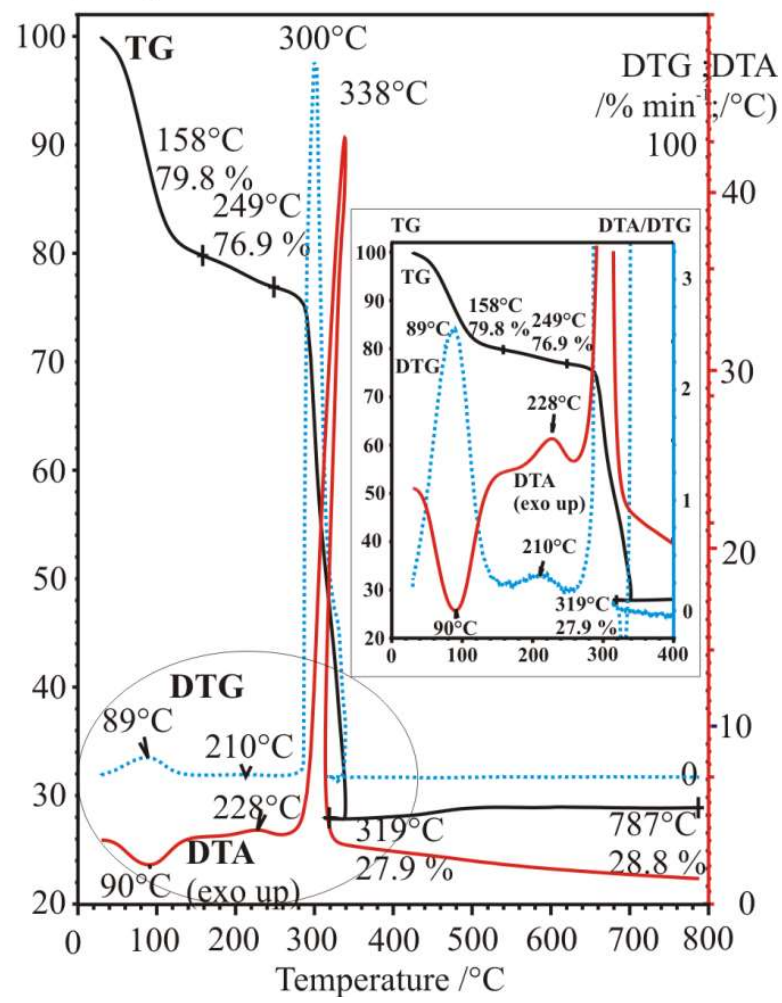

Fig. 4 TG (black), DTG (blue) and DTA (red) thermoanalytical response curves of HKUST-1 in $130 \mathrm{~cm}^{3} \mathrm{~min}^{-1}$ air flow (TG/DTA-MS measurement, initial mass $10.15 \mathrm{mg}$, heating rate $10^{\circ} \mathrm{C} \mathrm{min}^{-1}$ ). The inset shows the DTG (mass loss rate) and DTA (heat effects, exo up) curves, rearranged, and zoomed on the second mass loss stage between 150 and $250^{\circ} \mathrm{C}$. It is accompanied by slight exothermic heating.

The third and largest TG step is related to the thermal decomposition and combustion of the organic ligand. The concurrent large exothermic heat effect suddenly overheats the sample and its surroundings (beyond the expected program temperature) by about $40^{\circ} \mathrm{C}$ (Fig. 4). The anomalous shape of all the three thermoanalytical (TG, DTG, DTA) response curves in this temperature range, which is not addressed in other works, is due to overheating of the sample by the hugely exothermic character of this process. As the curves are recorded as a function of sample temperature, which suddenly increases greatly, it takes some time until the programmed temperature reaches the actual sample temperature (which meanwhile probably cools down), and then finally the sample temperature can again return to its upwards path. Careful observation of the region above ca $350{ }^{\circ} \mathrm{C}$ reveals a slight increase in the TG curve, which becomes constant above $520^{\circ} \mathrm{C}$. This phenomenon is also often ignored [16-18, 22]. The weight increase could be explained by a slow oxygen uptake in oxidation processes.

Fig. 5 compares the TG signals recorded in air and helium atmospheres. The curves are closely similar up to ca. $280{ }^{\circ} \mathrm{C}$, but significant differences appear beyond this temperature, where the structure collapses. While the simultaneous decarboxylation and combustion of the organic constituents of HKUST-1 is very rapid in air at about $300^{\circ} \mathrm{C}$, its thermal degradation in helium is less sharp and less complete, in agreement with the observations of other investigators $[16,18,22]$. In helium the weight loss by $400^{\circ} \mathrm{C}$ is ca. $30 \%$ smaller than in the oxidative medium, where the degradation products can burn out completely. In helium this step is followed by a long monotonically decreasing tail up to the end of the experiment at $800{ }^{\circ} \mathrm{C}$. 
TG, Weight $/ \%$

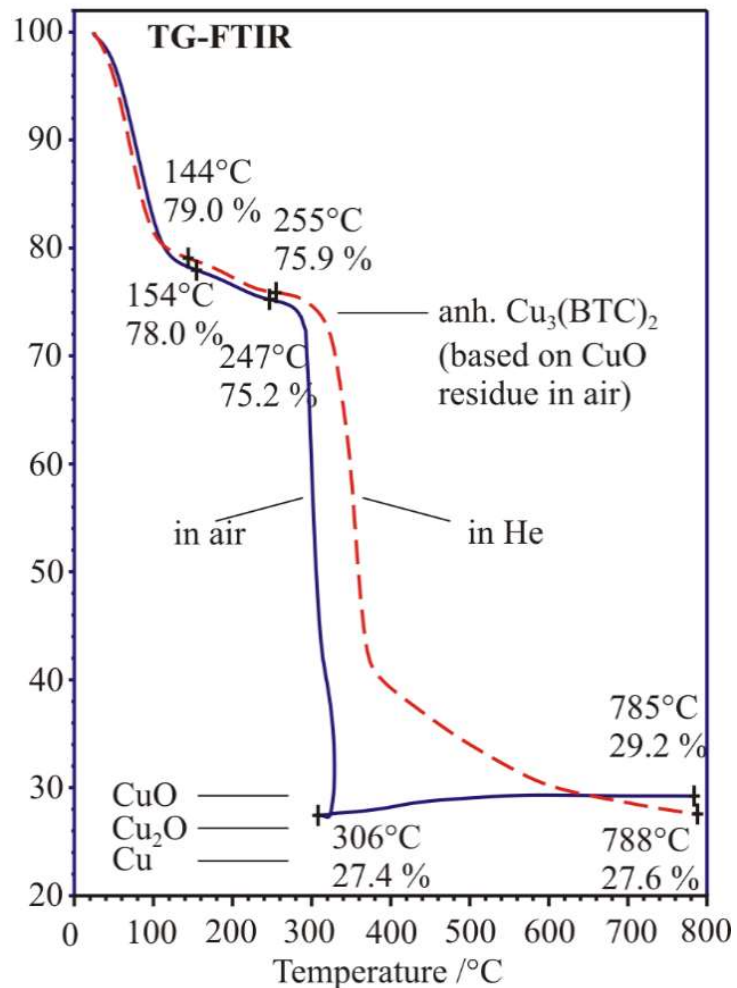

Fig. 5 Comparison of TG curves of the HKUST-1 in air (black solid line) and in helium (red dashed line) flow of $130 \mathrm{~cm}^{3} \mathrm{~min}^{-1}$ (TG-FTIR measurements, heating rate $10{ }^{\circ} \mathrm{C} \mathrm{min}{ }^{-1}$, initial mass 23.66 or $24.34 \mathrm{mg}$ in air and helium, respectively)

Table 2

Comparison of TG characteristics of low temperature decomposition stages of HKUST-1 in air and in helium.

\begin{tabular}{|c|c|c|c|c|c|c|c|}
\hline & & Stage 1 & & Stage 2 & & Stage 3 & \\
\hline Medium & Method & $\begin{array}{l}T \text { range } \\
{\left[{ }^{\circ} \mathrm{C}\right]}\end{array}$ & $\begin{array}{l}\text { Mass loss } \\
{[\%]}\end{array}$ & $\begin{array}{l}T \text { range } \\
{\left[{ }^{\circ} \mathrm{C}\right]}\end{array}$ & $\begin{array}{l}\text { Mass loss } \\
{[\%]}\end{array}$ & $\begin{array}{l}T \text { range } \\
{\left[{ }^{\circ} \mathrm{C}\right]}\end{array}$ & $\begin{array}{l}\text { Mass loss } \\
{[\%]}\end{array}$ \\
\hline \multirow{2}{*}{ Air } & TG-MS & $25-158$ & 20.2 & $158-249$ & 2.9 & $249-318$ & 48.9 \\
\hline & TG-FTIR & $25-154$ & 22.0 & $154-247$ & 2.7 & $247-305$ & 47.8 \\
\hline Helium & TG-FTIR & $25-146$ & 21.0 & $146-255$ & 3.1 & $255-384$ & 35.5 \\
\hline
\end{tabular}

\subsection{XRD phase analysis of solid residues and stoichiometric calculations of sample composition.}

The phase analysis of the powder XRD profiles of the samples heated to both $325{ }^{\circ} \mathrm{C}$ and $800{ }^{\circ} \mathrm{C}$ in air revealed that the mass increase in Fig. 4 above $320^{\circ} \mathrm{C}$ (when the oxidative thermal decomposition is already over) corresponds to the oxidation reaction

$$
\mathrm{Cu}_{2} \mathrm{O}_{(\mathrm{s})}+1 / 2 \mathrm{O}_{2(\mathrm{~g})} \rightarrow 2 \mathrm{CuO}_{(\mathrm{s})}
$$

While the solid residue obtained at $325{ }^{\circ} \mathrm{C}$ contained a mixture of $64 \mathrm{~m} / \mathrm{m} \% \mathrm{Cu}_{2} \mathrm{O}$ and $36 \mathrm{~m} / \mathrm{m} \%$ $\mathrm{CuO}$ (calculated by XRD RIR method), only $\mathrm{CuO}$ was detected in the $800{ }^{\circ} \mathrm{C}$ sample. That is, in contradiction to Refs. [18] and [22], in an oxidizing medium, $\mathrm{CuO}$ formation is completed only at a higher temperature, rather than simultaneously with the oxidation of the organic ligand. 
Based on the measured mass of the $\mathrm{CuO}$ residue at $800{ }^{\circ} \mathrm{C}$ in air $(28.8$ and $29.2 \%)$ and the stoichiometric composition $\mathrm{C}_{18} \mathrm{H}_{6} \mathrm{Cu}_{3} \mathrm{O}_{12}$, the anhydrous HKUST-1 content of the samples calculated in TG-MS and TG-FTIR experiments is 73.2 and $74.1 \%$, respectively. The deviation between these two values comes from using two different instruments and possible heterogeneity of the sample. (Based on the XRD identification and these values the solvothermal synthesis yields ca $83 \%$ solvent free material.) The residual masses read from the corresponding TG thermograms after the second stage are higher, 76.9 and $75.2 \%$, respectively. The discrepancy between the corresponding calculated and the measured values indicates that more organic material seems to be present in the MOF sample than expected from its stoichiometric composition: the organic/copper ratios are 2.34 and 2.22 instead of the theoretical 2.17 .

On the basis of the information that only $\mathrm{CuO}$ is formed in oxidative medium at high temperature, the purity of the HKUST-1 material reported in some of the reference works may be questionable $[16,22,40]$.

In helium at $800{ }^{\circ} \mathrm{C}$ the residue obtained contains $21 \mathrm{~m} / \mathrm{m} \% \mathrm{Cu}_{2} \mathrm{O}$ and $79 \mathrm{~m} / \mathrm{m} \% \mathrm{CuO}$, based on XRD RIR analysis. That is, the organic content of the sample only partially reduces the $\mathrm{Cu}$ (II) to its lower oxidation form (Fig. 5). This finding agrees well with the results of Ref. 13, which identifies both $\mathrm{Cu}_{2} \mathrm{O}$ and $\mathrm{CuO}$ in the residue obtained from $\mathrm{TG}$ analysis in nitrogen atmosphere at $600{ }^{\circ} \mathrm{C}$, but contradicts the findings of Hua Kuo et al., who identified only $\mathrm{CuO}$ in their sample obtained at $280{ }^{\circ} \mathrm{C}$ [15].

\subsection{Evolved gas analysis by mass spectrometry and FTIR spectroscopy in air}

Since only limited and contradicting information is available about the composition of the gaseous products evolving during the thermal decomposition of HKUST-1 $[15,16]$, the thermal decomposition of our sample was investigated both in oxidative and inert conditions by MS and FTIR analysis. It was thus possible to check the identity and the origin of the gaseous species evolved in the various decomposition stages.

Kaskel et al. investigating activated HKUST-1 $\left(120{ }^{\circ} \mathrm{C}, 12 \mathrm{~h}\right)$ by TG-MS in air, distinguished only two steps corresponding to the $\sim 30-200{ }^{\circ} \mathrm{C}$ and $\sim 300-320^{\circ} \mathrm{C}$ temperature ranges. Losses in the $211-300{ }^{\circ} \mathrm{C}$ range were ignored. In the first step only water was detected, although the synthesis was performed in an ethanol-water mixture. In the second step around $302{ }^{\circ} \mathrm{C}$, besides water and $\mathrm{CO}_{2}$, a fragment attributed to benzene $\operatorname{ring}(\mathrm{m} / \mathrm{z}=78)$ was identified [16]. Similarly, although in our case synthesis took place in an ethanol-water mixture and ethanol was used for washing, our findings reveal that the volatile components released from the non-activated sample up to ca $155^{\circ} \mathrm{C}$ consist only of water. That is, water alone, not ethanol, is retained within the pores and released by $155^{\circ} \mathrm{C}$ (Fig 6a).

Further evaluation of the in situ spectral series shows that in the frequently overlooked $160-260^{\circ} \mathrm{C}$ range a small but clearly detectable amount of organic vapour is released (Fig. 6b). The evidence of its $v(\mathrm{CH})$ stretching vibration band in the $2800-3000 \mathrm{~cm}^{-1}$ range indicates that it is an aliphatic molecule. (In the experiments carried out in helium, see Fig. 7b, it will be shown to be ethanol.) This organic vapour may come from esters formed between the ethanol and carboxylic groups of the $\mathrm{H}_{3} \mathrm{BTC}$ molecules situated on the crystal surface or in edge positions. In the second half of the same weight loss stage (from $200^{\circ} \mathrm{C}$ ) carbon dioxide and a limited amount of water vapour was also detected by FTIR (Fig. 6a and $6 \mathrm{c}$ ) and by MS $(\mathrm{m} / \mathrm{z}=18$, 17 , not shown), as well. We attribute these gases to the combustion products of aliphatic vapour. The thermal hydrolysis of these esterized surface regions may produce aliphatic fragments, most probably ethanol (see below), which, in turn, easily transforms to water and $\mathrm{CO}_{2}$ in an exothermic process (Fig. 4, inset) due to its low explosive limit (flash point $16.60{ }^{\circ} \mathrm{C}$ ). 


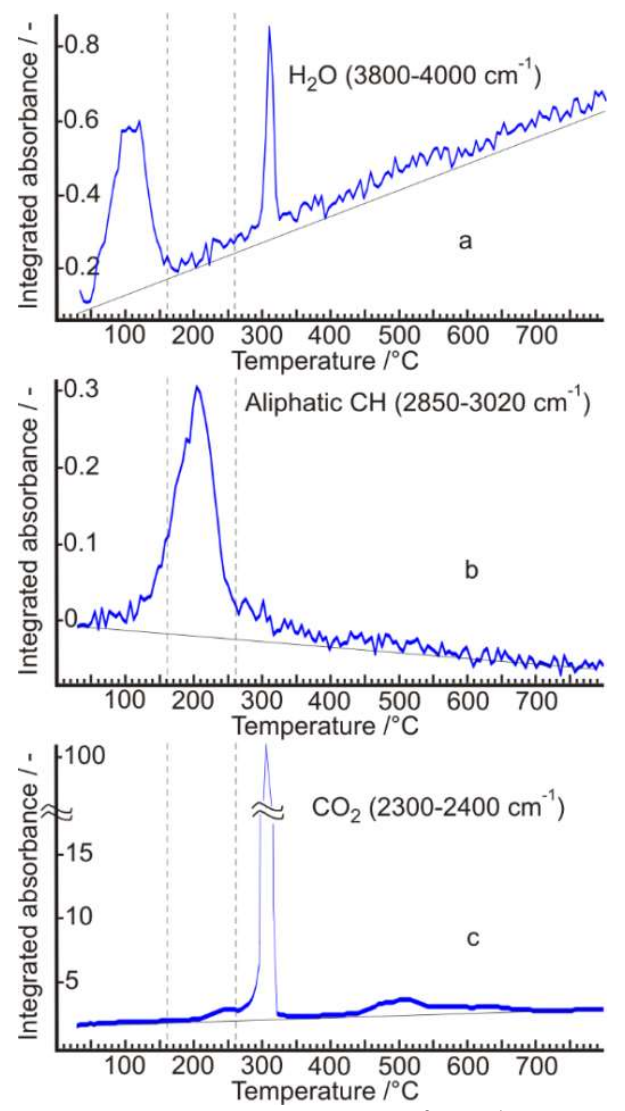

Fig. 6 Evolution of the gases and vapour emitted under $130 \mathrm{~cm}^{3} \mathrm{~min}^{-1}$ air flow, observed by TG-FTIR analysis. Release of (a) $\mathrm{H}_{2} \mathrm{O}$, (b) aliphatic fragments (determined through $v \mathrm{CH}$ ) and (c) $\mathrm{CO}_{2}$ are tracked by integration of their characteristic absorption bands in the FTIR spectra collected during a temperature ramp of $10^{\circ} \mathrm{C} \mathrm{min}-1$

(initial mass $23.66 \mathrm{mg}$ ).

In the third weight loss stage in the region $280-310^{\circ} \mathrm{C}$, the results of both auxiliary evolved gas identification methods indicate that the oxidative degradation (decarboxylation and burning) of the organic BTC ligands yields a huge amount of $\mathrm{CO}_{2}$ and significantly less water. A limited amount of aromatic volatile degradation products is also formed, as revealed by the $v \mathrm{CH})$ absorption band in the $3000-3100 \mathrm{~cm}^{-1}$ range. Due to its low explosive limit it cannot be identified in oxidative conditions. Our MS study also showed that in this step aromatic fragments $(\mathrm{m} / \mathrm{z}=77)$ were also released [16].

\subsection{Evolved gas analysis by FTIR spectroscopy in helium}

The study of thermal degradation in inert atmosphere was done in combination with the FTIR method (Fig. 7). The initial evolution of water up to $165{ }^{\circ} \mathrm{C}$ is very similar (Fig.7a) to that observed in oxidative conditions. In the $150-260{ }^{\circ} \mathrm{C}$ range a strong signal belonging to aliphatic volatile species was also observed in helium, while the water discharge in this temperature range was negligible (Fig. $7 \mathrm{a}$ and $7 \mathrm{~b}$ ). It follows that the source of the $3 \%$ weight loss is not chemisorbed water. In the absence of oxygen the aliphatic compound was successfully identified as ethanol in the spectrum taken at $201^{\circ} \mathrm{C}$ (Fig. 8a), based on a reference IR spectrum [43]. As already mentioned in section 3.4, we assume that mono-ethyl esters may form originally in the synthesis step between the ethanol and some of the carboxylic groups of the $\mathrm{H}_{3} \mathrm{BTC}$ molecules. When the diacidic mono-ethyl ester molecules are incorporated into the crystal in surface or edge positions, they probably serve as barriers that prevent further growth 
of the HKUST-1 crystal in the mother liquor. This may explain the particle size limitation of HKUST-1 crystal growth reported in the literature [44].
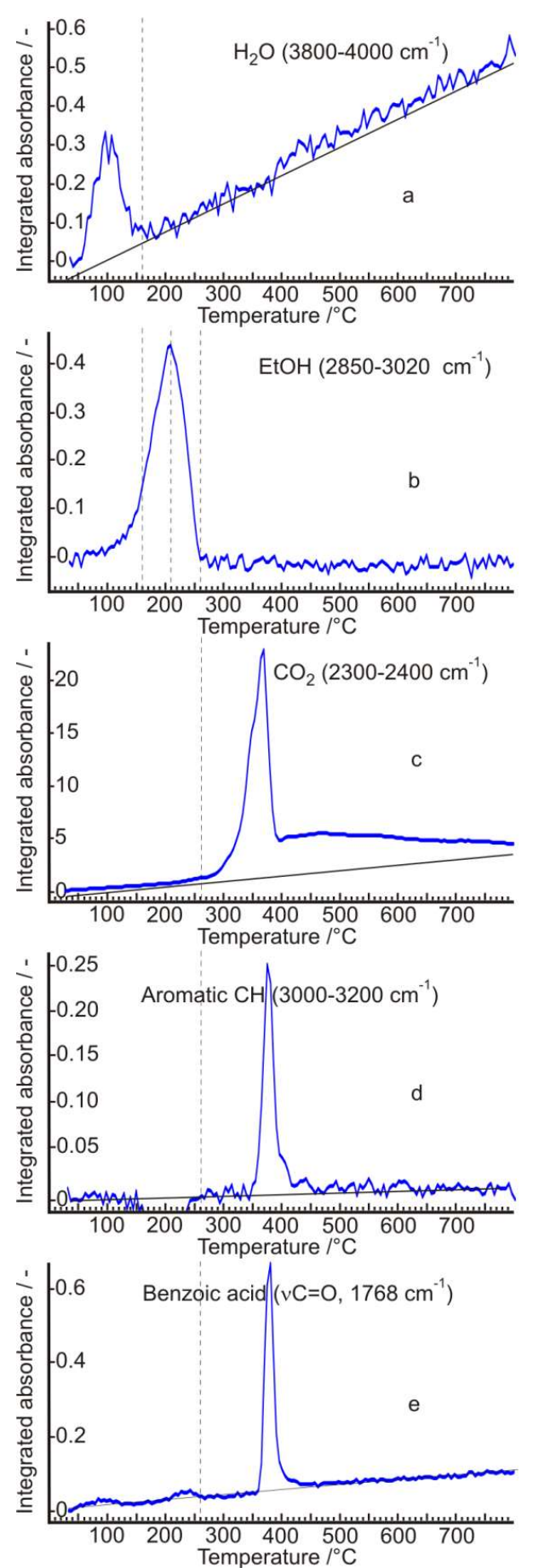

Fig. 7 Evolution of the gases and vapours emitted under helium flow of $130 \mathrm{~cm}^{3} \mathrm{~min}^{-1}$, observed by TG-FTIR analysis, Release of (a) $\mathrm{H}_{2} \mathrm{O}$, (b) ethanol (followed through $v \mathrm{CH}$ ), (c) $\mathrm{CO}_{2}$; (d) aromatic $v \mathrm{CH}$ and (e) benzoic acid (followed by $v \mathrm{C}=\mathrm{O}$ vibration band at $1768 \mathrm{~cm}^{-1}$ ) are tracked by integration of their characteristic absorption bands in the FTIR spectra collected during a temperature ramp of $10^{\circ} \mathrm{C} \mathrm{min}^{-1}$ (initial mass $24.34 \mathrm{mg}$ ).

Furthermore, this observation also shows that the water retained in the pores is completely released by $155^{\circ} \mathrm{C}$. This water amounts to 9.3 and $9.5 \mathrm{~mol} / \mathrm{HKUST}-1$ unit, similar to observations of other investigators. If liquid water structure were assumed, the pore volume $V_{\text {tot }}$ measured after activation would allow accommodation of ca. $17 \mathrm{~mol} / \mathrm{HKUST}-1$ unit. This 
ambiguity may suggest that the structure of the retained water is different from that of the bulk liquid state.
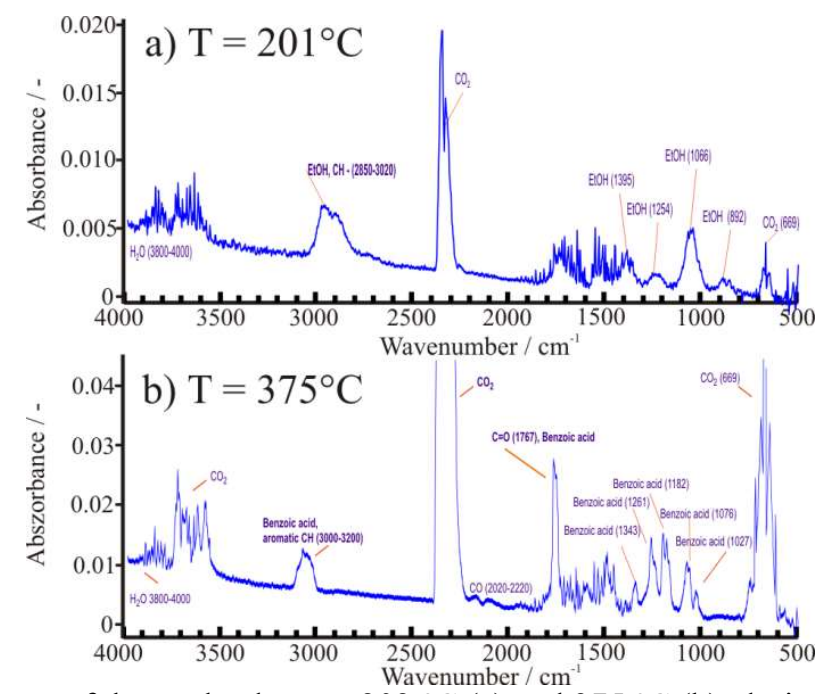

Fig. 8 FTIR spectra of the evolved gas at $202^{\circ} \mathrm{C}$ (a) and $375^{\circ} \mathrm{C}(\mathrm{b})$, during the TG-FTIR analysis in helium flow of $130 \mathrm{~cm}^{3} \mathrm{~min}^{-1}$ (heating rate $10{ }^{\circ} \mathrm{C} \mathrm{min}-1$, initial mass $24.34 \mathrm{mg}$ ).

In the $255-400{ }^{\circ} \mathrm{C}$ region the release of $\mathrm{CO}_{2}(\mathrm{Fig} .7 \mathrm{c})$ is first the result of the decarboxylation of some BTC ligands. Between 350 and $400{ }^{\circ} \mathrm{C}$ aromatic volatile species containing certain carbonyl $(\mathrm{C}=\mathrm{O})$ groups were observed (Figs. $7 \mathrm{~d}$ and $7 \mathrm{e})$. The simultaneous liberation of $\mathrm{C}=\mathrm{O}\left(\right.$ at $\left.1768 \mathrm{~cm}^{-1}\right)$ and the aromatic $\mathrm{CH}$ vibration $\left(3000-3100 \mathrm{~cm}^{-1}\right)$ suggests that the decomposition of the aromatic BTC ligands results, among others, in the formation of benzoic acid, as confirmed by the FTIR spectra of the gaseous mixture at $375^{\circ} \mathrm{C} \mathrm{(Fig.} \mathrm{8b)} \mathrm{[43].}$

FTIR also makes it possible to monitor the degradation in the elongated tail in Fig. 5 above $384{ }^{\circ} \mathrm{C}$. The mass loss in this high temperature range is related to slow $\mathrm{CO}_{2}$ and $\mathrm{CO}$ elimination. It can also be concluded that the water signal in this temperature range is considerably lower in helium than in air, since in the inert medium the $\mathrm{C}, \mathrm{H}$ and $\mathrm{Cu}$ atoms compete for the oxygen present in the MOF. The thermal degradation of HKUST-1 in vacuum has also been studied by Dathe et al. [15], using MS as auxiliary technique. They found that water was released in two steps (around 100 and $210^{\circ} \mathrm{C}$ ) prior to the thermal degradation of the organic ligand. In the $320-380^{\circ} \mathrm{C}$ range they identified $\mathrm{CO}_{2}$, but neither ethanol nor aromatic benzoic acid by-products.

\section{Conclusions}

The outstanding analytical power of TG was utilised to study HKUST-1 obtained by solvothermal synthesis below $100{ }^{\circ} \mathrm{C}$ in aqueous ethanol medium. XRD studies showed that the sample was free from metallic $\mathrm{Cu}$ and $\mathrm{Cu}_{2} \mathrm{O}$. TG measurements in both oxidative (air) and inert (helium) atmospheres were coupled in situ with MS and FTIR evolved gas analytical instruments. The TG/DTA measurement carried out in air up to $800^{\circ} \mathrm{C}$ reveal a sharp exotermic heat effect of simultaneous decarboxylation and combustion of HKUST-1 samples at around $280-300{ }^{\circ} \mathrm{C}$, that suddenly raises the sample temperature by about $40{ }^{\circ} \mathrm{C}$. The almost complete oxidative elimination of organic constituents occurs in form of $\mathrm{CO}_{2}$ and $\mathrm{H}_{2} \mathrm{O}$, leaving behind a mixture of copper-oxides $\left(\mathrm{Cu}_{2} \mathrm{O}\right.$ and $\left.\mathrm{CuO}\right)$ at $325^{\circ} \mathrm{C} . \mathrm{Cu}_{2} \mathrm{O}$ is oxidized slowly but quantitatively to $\mathrm{CuO}$ by $800^{\circ} \mathrm{C}$. In this way, from the residual amount of $\mathrm{CuO}$ observed at $800^{\circ} \mathrm{C}$, reliable stoichiometric calculations of weight levels corresponding to the copper content, the anhydrous 
metal organic framework, and various hydrated/solvated forms can be carried out and compared.

Evaluation of the TG-FTIR spectra obtained in helium showed that the mass loss of about $3 \%$ in the $160-260{ }^{\circ} \mathrm{C}$ range corresponds to ethanol vapour, which was not detected at all in the first stage up to $150^{\circ} \mathrm{C}$. The thermolytic release of ethanol is postulated to come from monoethylesters of the $\mathrm{H}_{3} \mathrm{BTC}$ ligands, which form during the synthesis on the outer surfaces of HKUST-1 crystals and which block further growth of the crystals. During the activation step between 150 and $250{ }^{\circ} \mathrm{C}$ they are thermally hydrolyzed. Thermolysis of such blocking esters may also be the reason for of the elevated activation temperature. The process is usually carried out at $180^{\circ} \mathrm{C}$ in vacuum. Further heating of the sample in helium around $375^{\circ} \mathrm{C}$ resulted in the liberation of carbon dioxide. Also, benzoic acid vapour, as one of the degradation products, was detected by the FTIR gas cell. The final residue at $800^{\circ} \mathrm{C}$ in helium was a mixture of copper oxides, identified by XRD.

Acknowledgement

We express our gratitude to Mr. D. Ábrahám and Mr. Gy. Bosznai for their technical support.

Funding

This work was supported by the Hungarian grant OTKA NN110209 and the CONCERT-EN046 NASEMS (JAPAN) project. 


\section{References}

[1] Schlichte K, Kratzke T, Kaskel S. Improved synthesis, thermal stability and catalytic properties of the metal-organic framework compound $\mathrm{Cu}_{3}(\mathrm{BTC})_{2}$. Microporous and Mesoporous Materials. 2004;73:81-8. http://dx.doi.org/10.1016/j.micromeso.2003.12.027.

[2] Horike S and Kitagawa S. Design of Porous Coordination Polymers/Metal-Organic Frameworks: Past, Present and Future in: Farrusseng D. (Eds.), Metal-organic frameworks applications from catalysis to gas storage. Wiley-VCH Verlag GmbH \& Co. KGaA. 2011; 320. http://dx.doi.org/10.1002/9783527635856.ch1.

[3] Ameloot R, Vermoortele F, Hofkens J, De Schryver FC, De Vos DE, Roeffaers MBJ. Threedimensional visualization of defects formed during the synthesis of metal-organic frameworks: A fluorescence microscopy study. Angew Chem Int Ed. 2013;52:401-5. http://dx.doi.org/10.1002/anie.201205627.

[4] García-García P, Müller M, Corma A. MOF catalysis in relation to their homogeneous counterparts and conventional solid catalysts. Chem Sci. 2014;5: 2979-3007. http://dx.doi.org/10.1039/C4SC00265B.

[5] Zeitler TR, Allendorf MD, Greathouse JA. Grand canonical Monte Carlo simulation of lowpressure methane adsorption in nanoporous framework materials for sensing applications. J. Phys. Chem. C. 2012;116:3492-502. http://dx.doi.org/10.1021/jp208596e.

[6] Chui SSY, Lo SMF, Charmant JPH, Orpen AG, Williams ID. A chemically functionalizable nanoporous material $\quad\left[\mathrm{Cu}_{3}(\mathrm{TMA})_{2}\left(\mathrm{H}_{2} \mathrm{O}\right)_{3}\right]_{n}$. Science. 1999;283:1148-50. http://dx.doi.org/10.1126/science.283.5405.1148.

[7] Hendon $\mathrm{CH}$, Walsh A. Chemical principles underpinning the performance of the metalorganic framework HKUST-1. Chem Sci. 2015;6:3674-83. http://dx.doi.org/10.1039/C5SC01489A.

[8] Supronowicz B, Mavrandonakis A, Heine T. Interaction of biologically important organic molecules with the unsaturated copper centers of the HKUST-1 metal organic framework: An ab-initio study. J Phys Chem C. 2015;119:3024-32. http://dx.doi.org/10.1021/jp507144w.

[9] Prestipino C, Regli L, Vitillo JG, Bonino F, Damin A, Lamberti C, Zecchina A, Solari PL, Kongshaug KO, Bordiga S. Local structure of framework $\mathrm{Cu}$ (II) in HKUST-1 metallorganic framework: spectroscopic characterization upon activation and interaction with adsorbates. Chem Mater. 2006;18:1337-46. http://dx.doi.org/10.1021/cm052191g.

[10] Chowdhury P, Bikkina C, Meister D, Dreisbach F, Gumma S. Comparison of adsorption isotherms on $\mathrm{Cu}$-BTC metal organic frameworks synthesized from different routes. Microporous and Mesoporous Materials. 2009;117:406-13. http://dx.doi.org/10.1016/j.micromeso.2008.07.029.

[11] Seo YK, Hundal G, Jang IT, Hwang YK, Jun CH, Chang JS. Microwave synthesis of hybrid inorganic-organic materials including porous $\mathrm{Cu}_{3}(\mathrm{BTC})_{2}$ from $\mathrm{Cu}(\mathrm{II})$-trimesate mixture. Microporous and Mesoporous Materials. 2009;119:331-37. http://dx.doi.org/10.1016/j.micromeso.2008.10.035.

[12] Liang Z, Marshall M, Chaffee AL. $\mathrm{CO}_{2}$ adsorption-based separation by metal organic framework (Cu-BTC) versus zeolite (13X). Energy \& Fuels. 2009;23:2785-89. http://dx.doi.org/10.1021/ef800938e.

[13] Liu Y, Zhang T, Wu W, Jiang S, Zhang H, Li B. Water mediated promotion of direct oxidation of benzene over the metal-organic framework HKUST-1. RSC Adv. 2015;5:5602027. http://dx.doi.org/10.1039/c5ra05595d.

[14] Qiu W, Wang Y, Li C, Zhan Z, Zi X, Zhang G, Wang R, He H. Effect of activation temperature on catalytic performance of CuBTC for CO oxidation. Chin J Catal. 2012;33:98692. http://dx.doi.org/10.1016/S1872-2067(11)60389-6. 
[15] Dathe H, Peringer E, Roberts V, Jentys A, Lercher JA. Metal organic frameworks based on $\mathrm{Cu}^{2+}$ and benzene-1,3,5-tricarboxylate as host for $\mathrm{SO}_{2}$ trapping agents. $\mathrm{C} \mathrm{R}$ Chimie. 2005;8:753-63. http://dx.doi.org/10.1016/j.crci.2004.10.018.

[16] Bö1hmann W, Pöppl A, Sabo M, Kaskel S. Characterization of the metal organic framework compound $\mathrm{Cu}_{3}$ (benzene-1,3,5-tricarboxylate) $)_{2}$ by means of ${ }^{129} \mathrm{Xe}$ nuclear magnetic and electron paramagnetic resonance spectroscopy. J Phys Chem B. 2006;110:20177-81. http://dx.doi.org/10.1021/jp063074r.

[17] Sorribas S, Kudasheva A, Almendro E, Zornoza B, de la Iglesia Ó, Téllez C, Coronas J. Pervaporation and membrane reactor performance of polyimide based mixed matrix membranes containing MOF HKUST-1. Chemical Engineering Science. 2015;124:37-44, and Supplementary data. http://dx.doi.org/10.1016/j.ces.2014.07.046.

[18] Banerjee A, Singh U, Aravindan V, Srinivasan M, Ogale S. Synthesis of CuO nanostructures from $\mathrm{Cu}$-based metal organic framework (MOF-199) for application as anode for Li-ion batteries. Nano Energy. 2013;2:1158-63. http://dx.doi.org/10.1016/j.nanoen.2013.04.008.

[19] Yang Y, Shukla P, Wang S, Rudolph V, Chen XM, Zhu Z. Significant improvement of surface area and $\mathrm{CO} 2$ adsorption of $\mathrm{Cu}-\mathrm{BTC}$ via solvent exchange activation. RSC Adv. 2013;3:17065-72. http://dx.doi.org/10.1039/C3RA42519C.

[20] Nobar SN, Farooq S. Experimental and modeling study of adsorption and diffusion of gases in $\mathrm{Cu}$-BTC. Chemical Engineering Science. 2012;84:801-13. http://dx.doi.org/10.1016/j.ces.2012.05.022.

[21] Israr F, Kim DK, Kim Y, Oh SJ, Ng KC, Chun W. Synthesis of porous Cu-BTC with ultrasonic treatment: Effects of ultrasonic power and solvent condition. Ultrasonics Sonochemistry. 2016;29:186-93. http://dx.doi.org/10.1016/j.ultsonch.2015.08.023.

[22] Liu J, Culp JT, Natesakhawat J, Bockrath BC, Zande B, Sankar SG, Garberoglio G, Johnson JK. Experimental and theoretical studies of gas adsorption in $\mathrm{Cu}_{3}(\mathrm{BTC})_{2}$ : An effective activation procedure. J Phys Chem C. 2007;111:9305-13, and Supporting data. http://dx.doi.org/10.1021/jp071449i.

[23] Bombicz P, Madarász J, Forizs E, Czugler M, Pokol G, Gál S, Kálmán A. Crystal structure and thermal characterisation of a theophyllinato $\mathrm{Cu}(\mathrm{II})$ complex with benzylamine.

Z. Kristallogr. 2000;215:317-21. ISSN: 00442968.

[24] Bombicz P, Madarász J, Forizs E, Foch I. Structure and thermal behaviour of (SPY-5-

12)-(2-aminoethanol-N)-(2-aminoethanol-N,O)bis(theophyllinato)copper(II) dihydrate, a model for DNA-metal interactions. Polyhedron. 1997;16:3601-7.

http://dx.doi.org/10.1016/S0277-5387(97)00104-6.

[25] Madarász J, Bombicz P, Czugler M, Pokol G. Comparison of theophyllinato $\mathrm{Cu}(\mathrm{II})$ complexes of ethanolamine and diethanolamine: Part 2. Structure and thermal study of the dimeric complex with diethanolamine. Polyhedron, 2000;19:457-46. http://dx.doi.org/10.1016/S0277-5387(99)00386-1.

[26] Madarász J, Bombicz P, Okuya M, and Kaneko S. Thermal decomposition of thiourea complexes of $\mathrm{Cu}(\mathrm{I}), \mathrm{Zn}(\mathrm{II})$, and $\mathrm{Sn}(\mathrm{II})$ chlorides as precursors for the spray pyrolysis deposition of sulfide thin films, Solid State Ionics. 2001:141-142:439-446.

http://dx.doi.org/10.1016/S0167-2738(01)00740-8.

[27] Madarász J. Evolved gas analyses on a mixed valence copper(I,II) complex salt with thiosulfate and ammonia by in situ TG-EGA-FTIR and TG/DTA-EGA-MS. J. Thermal Anal. Calorim. 2009;97:111-116. http://dx.doi.org/10.1007/s10973-009-0236-8. 
[28] Wang F, Guo H, Chai Y, Li Y, Liu C. The controlled regulation of morphology and size of HKUST-1 by "coordination modulation method". Microporous and Mesoporous Materials. 2013;173:181-8. http://dx.doi.org/10.1016/j.micromeso.2013.02.023.

[29] Allen, FH. The Cambridge structural database: a quarter of a million crystal structures and rising. Acta Cryst 2002;B58:380-8. http://dx.doi.org/10.1107/S0108768102003890.

[30] Macrae CF, Bruno IJ, Chisholm JA, Edgington PR, McCabe P, Pidcock E, et al. Mercury CSD 20 - new features for the visualization and investigation of crystal structures. J Appl Cryst 2008;41:466-70. http://dx.doi.org/10.1107/S0021889807067908.

[31] Brunauer S, Emmett P, Teller E. Adsorption of Gases in Multimolecular Layers. J. Am. Chem. Soc. 1938;60:309-19. http://dx.doi.org/10.1021/ja01269a023.

[32] Langmuir I. The constitution and fundamental properties of solids and liquids. Part I. Solids.. J. Am. Chem. Soc. 1916;38:2221-95. http://dx.doi.org/10.1021/ja02268a002.

[33] CSD refcode FIQCEN, Experimental Crystal Structure Determination by S.S.-Y.Chui, S.M.-F.Lo, J.P.H.Charmant, A.G.Orpen, I.D.Williams [our ref.No.6]. Deposited on: 4/1/1999, CCDC: 112954 , http://dx.doi.org/10.5517/cc3sjp2.

[34] CSD refcode DOTSOV42, Experimental Crystal Structure Determination through neutron diffraction by Shengchang Xiang, Wei Zhou, J.M.Gallegos, Yun Liu, Banglin Chen, (J. Am. Chem. Soc., 2009, 131, 12415, DOI: 10.1021/ja904782h). Deposited on 17/11/2009, CCDC: 755080:, http://dx.doi.org/10.5517/cctbqf8.

[35] PDF: 00-062-1183, Copper benzene-1,3,5-tricarboxylate trihydrate (copper trimesate trihydrate, $\mathrm{Cu}_{3}\left(\mathrm{C}_{9} \mathrm{H}_{3} \mathrm{O}_{6}\right)_{2} \cdot 3 \mathrm{H}_{2} \mathrm{O}$. Prepared by mechanosynthesis from copper nitrate and benzene-1,3,5-tricarboxylic acid precursors by Audebrand, N., Univ. de Rennes I, Laboratoire Sciences Chimiques de Rennes, France., ICDD Grant-in-Aid, (2011).

[36] PDF: 00-064-0936, Bis(benzene 1,3,5-tricarboxylato)tricopper(II) hydrate (Basolite $\mathrm{C} 300), \mathrm{Cu}_{3}\left(\left(\mathrm{O}_{2} \mathrm{C}\right)_{3} \mathrm{C}_{6} \mathrm{H}_{3}\right)_{2} \bullet 9.4 \mathrm{H}_{2} \mathrm{O}$. Commercial material, prepared by BASF and purchased from Sigma-Aldrich. Pattern measured in equilibrium with the atmosphere. The initially dehydrated material absorbed water from the atmosphere. Kaduk, J., Poly Crystallography Inc., Naperville, IL, USA; Wong-Ng, W., NIST, Gaithersburg, MD, USA., ICDD Grant-in-Aid, (2012).

[37] PDF: 00-065-1028, Copper benzene-1,3,5-tricarboxylate (Basolite C300; Cu-BTC MOF; HKUST-1, Purchased commercial material (Lot STBC4614V)), $\mathrm{Cu}_{3}\left(\left(\mathrm{O}_{2} \mathrm{C}_{3} \mathrm{C}_{6} \mathrm{H}_{3}\right)_{2}\right.$. Sample was dehydrated at $423 \mathrm{~K}$ overnight under vacuum. Pattern measured at beam line 11-BM, (goniometer radius $1000 \mathrm{~mm}$ ) Advanced Photon Source, Argonne National Laboratory, Lement, Illinois, USA. Data collected using Debye-Scherrer geometry. Kaduk, J., Poly Crystallography Inc., Naperville, IL, USA., ICDD Grant-in-Aid, (2014).

[38] Wang QM, Shen D, Bülow M, Lau ML, Deng S, Fitch FR, Lemcoff NO, Semanscin J. Metallo-organic molecular sieve for gas separation and purification. Microporous and Mesoporous Materials. 2002;55:217-30. http://dx.doi.org/10.1016/S1387-1811(02)00405-5.

[39] Raoof JB, Hosseini SR, Ojani R, Mandegarzad S. MOF-derived Cu/nanoporous carbon composite and its application for electro-catalysis of hydrogen evolution reaction. Energy. 2015;90:1075-81. http://dx.doi.org/10.1016/j.energy.2015.08.013.

[40] Lin KS, Adhikari AK, Ku CN, Chiang CL, Kuo H. Synthesis and characterization of porous HKUST-1 metal organic frameworks for hydrogen storage. International journal of hydrogen energy. 2012;37:13865-71. http://dx.doi.org/10.1016/j.ijhydene.2012.04.105.

[41] Gu ZG, Fu H, Neumann T, Xu ZX, Fu WQ, Wenzel W, Zhang L, Zhang, J, Wöll C. Chiral Porous Metacrystals: Employing Liquid-Phase Epitaxy to Assemble Enantiopure Metal-Organic Nanoclusters into Molecular Framework Pores. ACS Nano. 2016;10:977-83. http://dx.doi.org/10.1021/acsnano.5b06230. 
[42] Wee LH, Lohe MR, Janssens N, Kaskel S, Martens JA. Fine tuning of the metal-organic framework $\mathrm{Cu}_{3}$ (BTC) $)_{2}$ HKUST-1 crystal size in the $100 \mathrm{~nm}$ to 5 micron range. J Mater Chem. 2012;22:13742-46. http://dx.doi.org/10.1039/c2jm31536j.

[43] NIST Chemistry Webbook, Standard Reference Database Number 69, National Institute of Standards and Technology, Material Measurement Laboratory. http://webbook.nist.gov/cgi/cbook.cgi?ID=C554950\&Mask=200. (accessed 29 Apr 2016).

[44] Huo J, Brightwell M, Hankari SE, Garai A, Bradshaw D. A versatile, industrially relevant, aqueous room temperature synthesis of HKUST-1 with high space-time yield. J. Mater. Chem. A. 2013;1:15220-23. http://dx.doi.org/10.1039/C3TA14409G. 